\title{
SPORTS ORIENTATION DURING LEARNING TEAM OR INDIVIDUAL SPORTS USING A SPORT EDUCATION MODEL
}

\author{
Agi Ginanjar ${ }^{* *}$, Adang Suherman ${ }^{2}$, Tite Juliantine ${ }^{3}$, Yusuf Hidayat ${ }^{4}$ \\ ${ }^{1}$ STKIP Nahdlatul Ulama Indramayu, ${ }^{2,3,4}$ Universitas Pendidikan Indonesia Indonesia \\ *e-mail: agiginanjar@stkipnu.ac.id
}

\begin{abstract}
Since competition activities can improve sportsmanship, moral development, motivation, and prepare students in the "real world", competition activities (sports orientation) in physical education is very necessary. A strategy that is proposed to stimulate sports orientation in physical education in this study is a Sport Education Model (SEM). The purpose of this study was to determine the differences between team sports and individual sports when using SEM, towards sports orientation in physical education for junior high school students. The research method uses true experiments with posttestonly control group design. The participants in this study were 80 grade seventh junior high school students. Using the Sport Orientation Questionnaire (SOQ), the data was analysed using independent samples t-test. The results stated that there were significant differences between the two conditions. The findings suggests that sports orientation in SEM team sports are more influenced by goal orientation is in accord with the statement that achievement in sports competition (sports orientation) depends on goal orientation, but not at SEM individual sports.
\end{abstract}

Keywords: sport education model, sports orientation, physical education

\section{ORIENTASI OLAHRAGA DALAM PEMBELAJARAN OLAHRAGA TIM ATAU OLAHRAGA INDIVIDU MENGGUNAKAN SPORT EDUCATION MODEL}

\begin{abstract}
Abstrak: Semenjak kegiatan kompetisi dapat meningkatkan sportivitas, perkembangan moral, motivasi, dan menyiapkan siswa dalam "dunia nyata", aktivitas kompetisi (orientasi olaharaga) dalam pendidikan jasmani sangat diperlukan. Salah satu strategi yang dapat menangani orientasi olahraga dalam pendidikan jasmani dapat menggunakan Sport Education Model (SEM). Tujuan penelitian ini adalah untuk mengetahui perbedaan SEM cabang olahraga tim dan SEM cabang olahraga individu terhadap orientasi olahraga dalam pendidikan jasmani siswa SMP. Metode penelitian menggunakan true eksperimen dengan posttest-only control group design. Partisipan dalam penelitian ini sebanyak 80 siswa SMP kelas VII. Menggunakan Sport Orientation Questionnaire (SOQ), data dianalisis dengan independent samples t-test. Hasil penelitian menunjukkan bahwa terdapat perbedaan SEM cabang olahraga tim dan SEM cabang olahraga individu terhadap orientasi olahraga dalam pendidikan jasmani siswa SMP. Temuan menunjukan bahwa orientasi olahraga pada kelompok SEM cabang olahraga tim lebih dipengaruhi oleh orientasi tujuan sesuai dengan pernyataan bahwa pencapaian dalam kompetisi olahraga (orientasi olahraga) tergantung pada orientasi tujuan, tetapi tidak pada kelompok SEM cabang olahraga individu.
\end{abstract}

Kata Kunci: sport education model, orientasi olahraga, pendidikan jasmani

\section{PENDAHULUAN}

Di Indonesia bahkan di dunia banyak berkembang isu yang berkaitan dengan pendidikan jasmani seperti status terbawah, standar kompetensi professional rendah, alokasi waktu, alokasi dana, ketenagaan, mutu proses belajar dan mengajar (PBM), asesmen dan evaluasi, kegiatan ekstrakulikuler, dan identifikasi dan pengembangan bakat olahraga jalur persekolahan (talented \& gifted students) (Komnaspenjasor, 2009). Berbagai isu tersebut berkaitan dengan pernyataan bahwa kompetensi profesional guru pada saat pre-service maupun in-service masih sangat kurang (Maksum, 2008). Hampir seluruh guru pendidikan jasmani di setiap sekolah memakai model pembelajaran langsung, guru memegang kendali dalam pembelajaran sedangkan siswa mengikuti 
pembelajaran yang diberikan oleh guru sehingga dengan pembelajaran langsung gagal untuk mempersiapkan peserta didik secara tepat untuk kompleksitas permainan (Kirk \& Mcdonald, 1998).

Pembelajaran pendidikan jasmani yang dipusatkan pada model pengajaran langsung menghasilkan tingkat ketidakaktifan murid yang tinggi (Roberts \& Fairclough, 2011). Apalagi diperkuat fakta penelitian yang menunjukkan bahwa para guru menghabiskan sebagian besar waktu mereka menggunakan gaya pengajaran langsung (Curtner-Smith, Todorovich, McCaughtry, \& Lacon, 2001). Selain itu, permasalahan yang berhubungan dengan tujuan dari kompetensi dasar di dalam kurikulum yang sedang berjalan yang lebih menitikberatkan kepada keterampilan kecabangan olahraga seperti mempraktikkan variasi dan kombinasi teknik dasar berbagai bentuk permainan bola besar, permainan bola kecil, atletik, beladiri, ritmik, dan aquatik (Kemendikbud, 2012).

Sebenarnya kurikulum juga harus memuat pendidikan moral, yaitu jiwa kompetitif siswa yang ditandai dengan adanya kompetisi. Kompetisi memeriksa apa yang ia sajikan sebagai kritik 'kuat' dan 'lemah' yang sering dilontarkan terhadap keinginan moral untuk memiliki olahraga kompetitif sebagai bagian dari kurikulum pendidikan wajib (Arnold, 1989). Keunggulan dari kompetisi adalah meningkatkan sportivitas, perkembangan moral, motivasi, dan menyiapkan siswa dalam "dunia nyata"; siswa lebih memilih kegiatan kompetisi untuk membangun kepercayaan diri dan motivasi (Greendorfer, 1987; Kohn, 1986). Kesuksesan dan orientasi prestasi merupakan orientasi seseorang terhadap dominasi daya saing untuk dapat berpindah kepada arah yang lebih baik (Farshad, Jasem, \& Mohammad, 2013; Sheikh, Afshari, \& Sheikh, 2011) sehingga nilai olahraga kompetitif di sekolah diperlukan (Almond, 2014).

Dengan pandangan bahwa dalam kurikulum harus ada kegiatan kompetisi, maka dalam melaksanakan proses pembelajaran harus memiliki stategi yang tepat dalam mengelola proses pembelajaran tersebut agar dapat merekayasa proses pembelajaran yang mengarah kepada kegiatan kompetisi yang memiliki makna positif. Salah satu alat untuk membantu guru dalam PBM adalah dengan mengunakan model pembelajaran (Ginanjar, 2015). Untuk membantu siswa menjadi lebih aktif selama pelajaran olahraga, guru harus mampu dan mau memberikan pengajaran berkualitas dengan strategi pengajaran yang sesuai (Bryan \& Solmon, 2012).

Model pembelajaran yang diasumsikan dapat meningkatkan aktivitas siswa sehingga mencapai kegiatan kompetitif dalam mengikuti pembelajaran adalah menggunakan Sport Education Model (SEM). SEM merupakan bentuk model pembelajaran yang memadukan kemampuan dan kerja sama sebuah tim yang saling mendukung dalam sebuah musim olahraga (Siedentop, Hastie, \& van der Mars, 2011). Kemudian SEM merupakan bentuk model pembelajaran kurikulum yang berdasarkan kepada teori bermain secara berkompetisi dengan hasil kompetisi tergantung kepada keterampilan dan strategi (Jewett, Bain, \& Ennis, 1995). SEM dirancang untuk memberikan anak-anak dengan persaingan yang sesuai perkembangannya (Siedentop, et al., 2011).

Tujuan dari SEM adalah untuk mendorong setiap individu untuk mengembangkan keterampilan dan pemahaman yang diperlukan untuk berpartisipasi dalam kegiatan olahraga. Siswa yang terlibat dalam SEM akan menjadi terpelajar, antusias, dan olahragawan yang berkompeten (Siedentop, 1994), melalui enam karakteristik SEM yaitu musim, afiliasi, kompetisi formal, acara puncak, penyimpanan catatan, dan perayaan (Siedentop, 1994). Secara prosedur SEM disusun berdasarkan musim. Pada akhir musim akan ada kompetisi. Kompetisi tersebut akan ada persaingan untuk mencapai juara walaupun secara konteks menjadi juara bukanlah tujuan utama dari SEM sehingga akan memunculkan sikap kompetitif dalam mengikuti pembelajaran.

Hasil berbagai penelitian mengatakan bahwa SEM telah berhasil dalam proses pembelajaran. SEM dapat digunakan baik pada laki-laki maupun perempuan (McPhail, Gorely, Kirk, \& Kinchin, 2008). Dengan menggunakan SEM, siswa menikmati pembelajaran (McPhail, Kirk, \& Kinchin, 2004). Dengan menggunakan SEM siswa menikmati peran dalam pembelajaran (Hastie \& Sinelnikov, 2006). SEM menghasilkan siswa memiliki pemahaman yang lebih baik tentang permainan, kerja tim dan taktik (Carlson, 1995). Dengan menggunakan SEM 
siswa menikmati kerja sama (Hastie \& Curtnersmith, 2006). Dengan menggunakan SEM siswa menikmati permainan (Wallhead \& Ntoumanis, 2004). SEM lebih memberikan makna daripada aktivitas kelas tanpa menggunakan SEM dan diantara beberapa siswa menyatakan bahwa daya saing menggunakan kompetisi itu intens, adil, bahkan menarik dan menyenangkan (Bennett \& Hastie, 1997).

SEM bisa juga digunakan baik dalam cabang olahraga tim atau individu. SEM dibagi kedalam empat bidang olahraga baik olahraga yang bersifat tim ataupun bersifat individu sebagai berikut: 1) Racquet sports terdiri dari: badminton, racqquetball, table tennis, tennis. 2) Target sports terdiri dari archery, bowling, golf, fencing, riflery; 3) Team sports terdiri dari: volleyball, track and field, flag football, basketball, baseball, softball, cross country, swimming, soccer; dan 4) Martial arts terdiri dari: karate (Siedentop, 1994). Dalam penelitian ini pemilihan cabang olahraga untuk olahraga tim dengan menggunakan cabang olahraga bolabasket dan untuk olahraga individu dengan menggunakan cabang olahraga bulu tangkis.

Alasan memilih kedua cabang tersebut karena bola basket dan bulu tangkis merupakan cabang yang termasuk populer dan guru mengetahui aturan dan tata cara permainan cabang olahraga tersebut, kemudian kedua cabang tersebut terdapat di dalam kurikulum yang sedang berjalan, dan dalam bentuk permainan. Kedua cabang ini dapat dijadikan sebuah kompetisi olahraga yang membedakan secara permainan bola basket sering terjadi sentuhan atau benturan dengan lawan dan secara langsung sedangkan bulu tangkis dapat bersifat individu seperti satu lawan satu atau dua lawan dua, setiap pemain atau pasangan mengambil posisi berseberangan pada kedua sisi jaring di lapangan bulu tangkis yang dibatasi oleh net di bagian tengah untuk memisahkan daerah permainan yang satu dengan lainnya.

Dari keseluruhan pemaparan di atas, maka tujuan dari penelitian ini untuk mengetahui perbedaan SEM cabang olahraga tim dan SEM cabang olahraga individu terhadap orientasi olahraga dalam pendidikan jasmani siswa SMP.

\section{METODE}

Metode penelitian menggunakan true eksperimen dengan posttest-only control group design. Partisipan dalam penelitian ini sebanyak 174 siswa SMP kelas VII, berkaitan dengan posttest-only control group design yang harus menggunakan 40 orang sampel dari setiap kelompok (Fraenkel, Wallen, \& Hyun, 2013), sehingga kelas eksperimen dengan menggunakan SEM cabang olahraga bola basket dan kelas kontrol dengan cabang olahraga bulu tangkis menggunakan 40 orang setiap kelompoknya dengan total sebanyak 80 orang yang diambil secara random. Treatment yang digunakan oleh kedua kelompok tersebut menggunakan SEM yang digunakan dibagi ke dalam tiga tahap yaitu skill/tactical development, inter/intra team games with practices, dan postseason (Perlman, 2012). Ketiga tahap tersebut peneliti yakini dapat memberikan hasil penelitian yang diharapkan karena berdasarkan hasil karya Perlman (2010) yang diverifikasi pada dua titik waktu yaitu perencanaan dan implementasi dengan reliabilitas sebesar .96 pada perencanaan dan .92 pada implementasi. Treatment tersebut kemudian dikombinasikan dengan menggunakan gabungan dari berbagai model pembelajaran, yaitu direct instruction, cooperative, dan peer (Metzler, 2000; Siedentop, 1998).

Tahap skill/tactical development lebih menekankan kepada kemampuan keterampilan gerak olahraga yang akan digunakan, pada fase ini menggunakan direct instruction dan cooperative tipe Student Team Achievement Division (STAD). Tahap inter/intra team games with practices menekankan kepada kompetisi di dalam tim untuk menghadapi pertandingan antar tim pada tahap selanjutnya, pada fase ini menggunakan cooperative tipe Teams Games Tournaments (TGT) yang mana dalam TGT terdapat pertandingan dalam tim dan pertandingan antar tim, peer digunakan untuk mengetahui siswa yang memliki kemampuan yang baik (hasil pertandingan antar tim di dalam kelompoknya) melatih siswa yang kurang memiliki kemampuan yang baik. Tahap akhir atau disebut postseason merupakan refleksi dari tahapan-tahapan sebelumnya, ini merupakan akhir dari musim pembelajaran menggunakan kompetisi antar tim dengan adanya turnamen. Pelaksanaan treatment di dalam penelitian ini dilaksanakan satu minggu satu kali dengan total sebanyak 15 kali pertemuan dengan 5 pertemuan pada setiap tahap SEM yang digunakan. Setiap pertemuan diberi alokasi waktu selama 90 menit 
yang disesuaikan dengan alokasi mata pelajaran pendidikan jasmani di Indonesia. Untuk perbedaan treatment kedua kelompok dapat dilihat pada Tabel 1.

Dalam penelitian ini terdapat dua guru yang terlibat dalam menjalakan tretment yang telah dibuat, satu orang mengajar pada kelas eksperimen dan satu orang mengajar pada kelas kontrol. Kedua guru tersebut merupakan lulusan program magister yang pernah belajar tentang SEM walaupun belum pernah melakukan pembelajaran pendidikan jasmani dengan menggunakan SEM sebelumnya, dan telah mengajar di sekolah ini selama empat tahun lebih sama dengan ketika sekolah ini berdiri. Selain itu, kedua guru tersebut sudah mengetahui aturan bola basket dan bulu tangkis karena mereka belajar selama satu semester dalam penguasaan bola basket dan bulu tangkis baik peraturan permainan, perwasit, dan lain-lain. Siswa yang terlibat di dalam penelitian ini juga pernah terlibat dalam pembelajaran pendidikan jasmani dalam materi bola basket dan bulu tangkis dari sekolah dasar sampai sekarang.

Instrumen yang digunakan untuk mengukur orientasi olahraga menggunakan kuesioner orientasi olahraga atau Sport Orientation Questionnaire (SOQ) (Almond, 2014; Farshad, et al., 2013; Gill \& Deeter, 1988; Gill \& Dzewaltowski, 1988; Manouchehri \& Tojari, 2013; Petróczi, 2007; Skordilis, et al., 2001). SOQ telah digunakan secara luas dalam berbagai penelitian SOQ terdiri dari tiga subskala: 1) competitiveness (daya saing) terdiri atas 13 item; 2) winning orientation (orientasi kemenangan) terdiri atas 6 item; dan 3) goal orientation (orientasi tujuan) terdiri atas 6 item untuk setiap item soal dengan total seluruh item sebanyak 25 item soal. Instrumen tersebut diperuntukan untuk atlet dan telah divalidasi ke dalam pendidikan jasmani tingkat SMP dengan menggunakan analisis faktor konfirmatori dengan bantuan aplikasi IBM AMOS 24. Hasil yang didapat 15 item soal dapat digunakan dengan rincian subskala competitiveness (daya saing) sebanyak 7 item; 2) winning orientation (orientasi kemenangan) sebanyak 3 item; dan 3) goal orientation (orientasi tujuan) sebanyak 5 item dengan nilai $\mathrm{CMIN}=144.79$ dan $\mathrm{DF}=$ 87 dengan $\mathrm{CMIN} / \mathrm{DF}=1.66<2$. RMSEA $=$ .059 diantara $.05-.08$ dengan nilai NFI, PNFI,
CFI, IFI, RFI, GFI, AGFI dengan masingmasing nilai $.85, .71, .93, .94, .82, .90$, dan .86 yang diindikasikan diterima sehingga model pengukuran adalah baik. Berkaitan dengan pengambilan data, instrumen ini diberikan setelah program treatment diberikan pada pertemuan terakhir dengan alasan agar siswa masih merasakan antusiame hasil treatment yang telah diberikan sehingga diharapkan siswa dapat memberikan apa yang mereka rasa setelah program treatment berakhir.

Teknik analisis data dilakukan lewat teknik statistik deskriptif untuk melihat perbedaan ratarata, simpangan baku dan varian dari setiap data dengan bantuan IBM Statistical Package for the Social Sciences (SPSS) Statistics 24. Uji normalitas merupakan salah satu uji prasyarat yang digunakan untuk mengetahui apakah data tersebut berdistribusi normal atau baik yang dianalisis menggunakan uji shapiro-wilk dengan bantuan IBM SPSS Statistics 24. Uji homogenitas digunakan untuk mengetahui apakah suatu data atau sampel yang diambil berasal dari varian yang homogen atau tidak yang dianalisis menggunakan lavene statistic dengan bantuan IBM SPSS Statistics 24. Untuk mengetahui signifikansi data yang didapat dianalisi menggunakan independent samples t-test dengan bantuan IBM SPSS Statistics 24 .

\section{HASIL DAN PEMBAHASAN Hasil}

Darihasilanalisis datayang telah dilakukan pada kelompok SEM bola basket didapat $\overline{\mathrm{X}}=$ $60.88, s=4.72$, dan $S=22.32$. Pada kelompok SEM bulu tangkis didapat $=31.25, s=6.1$, dan $S=37.22$. Uji normalitas kelompok SEM bola basket sebesar .83 dengan signifikansi $.50>.05$, pada kelompok SEM bulu tangkis sebesar .71 dengan signifikansi $.70>.05$, dari data tersebut maka data kedua kelompok tersebut berdistribusi normal. Uji Homogenitas didapat nilai sebesar 2.94 dengan signifikansi $.09>.05$, maka kedua kelompok tersebut berasal dari data yang sama atau homogen. Kemudian uji hipotesis didapat $\mathrm{t}_{\text {hitung }}=73.4$ dengan signifikansi $.00<.05$ yang artinya terdapat perbedaan SEM cabang olahraga tim dan SEM cabang olahraga individu terhadap orientasi olahraga dalam pendidikan jasmani Siswa SMP. 
Tabel 1. Perbedaan Treatment Kelompok Penelitian

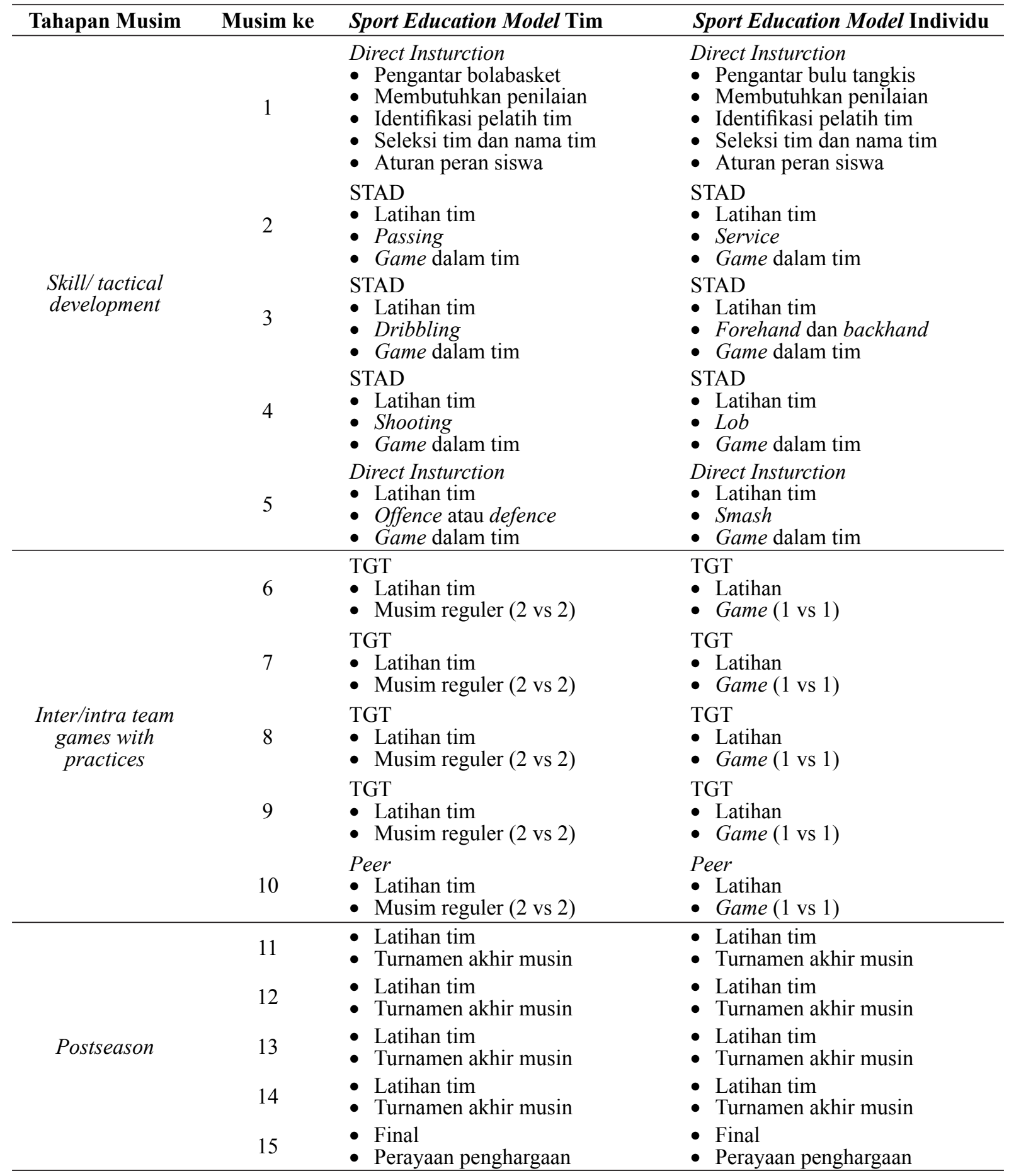

\section{Pembahasan}

Fokus di dalam penelitian ini untuk menguji perbedaan SEM cabang olahraga tim dan SEM cabang olahraga individu terhadap orientasi olahraga dalam pendidikan jasmani Siswa SMP. Hasil penelitian menyatakan bahwa SEM cabang olahraga tim memberikan tingkat signifikansi yang lebih tinggi dengan SEM cabang olahraga individu terhadap orientasi olahraga. Ini dapat disebabkan seperti yang telah dikatakan sebelumnya, secara sederhana permainan bola basket merupakan olahraga yang memiliki gerakan kompleks yang meliputi anggota tubuh seperti kaki, tangan, badan yang secara bersamaan bergerak. Ketika melakukan dribbling kaki bergerak melangkah baik dengan berjalan maupun berlari sambil tangan memantulmantulkan bola yang dilakukan dalam waktu bersamaan dalam suatu gerakan. 
Pola gerakan bola basket juga memiliki pola gerakan yang kompleks seperti berjalan, berlari, melompat yang merupakan gerakan yang paling dominan dalam bermain bola basket. Dalam permainan bola basket sering terjadi sentuhan atau benturan dengan lawan dan secara langsung seorang pemain dapat melakukan pelanggaran terhadap lawannya. Di pihak lain, dalam permainan bulu tangkis secara sederhana sama halnya dengan bola basket memiliki gerakan yang kompleks seperti memukul, berdiri, melangkah, bergeser, meloncat, berlari cepat tetapi dalam jarak yang relatif kecil sehingga buku tangkis memiliki gerakan cepat dengan frekuensi variasi gerakan eksplosif yang cukup banyak dan dalam bulu tangkis mengharuskan pemainnya memiliki tingkat akurasi yang tinggi. Permainan bulu tangkis dapat bersifat individu seperti satu lawan satu atau dua lawan dua, setiap pemain atau pasangan mengambil posisi berseberangan pada kedua sisi jaring di lapangan bulu tangkis yang dibatasi oleh net di bagian tengah untuk memisahkan daerah permainan yang satu dengan lainnya sehinga tidak terjadi sentuhan atau benturan dengan pemain lawan.

Selain itu, ini bisa disebabkan karena bola basket lebih cepat memulai permainan dalam pencapaian aktivitas fisik dan siswa tetap bergerak walaupun tidak memainkan bola (Perlman, 2012). Keterlibatan dalam SEM unit invasi (permainan menyerang seperti sepak bola, bola basket, dan lain-lain) memberikan perubahan dalam aktivitas pembelajaran (Hastie \& Trost, 2002; Perlman, 2012). Hasil ini mendukung dan memperluas SEM dalam berbagai proses pembelajaran (Carlson, 1995; Hastie \& Curtnersmith, 2006; Hastie \& Sinelnikov, 2006; McPhail, et al., 2004; Wallhead \& Ntoumanis, 2004). Sehingga penelitian ini memberikan pandangan bahwa SEM dapat digunakan dalam olahraga yang bersifat kompetisi. Dengan menggunakan SEM daya saing menggunakan kompetisi itu intens, adil, bahkan menarik dan menyenangkan (Bennett \& Hastie, 1997).

Hal itu juga menjadi harapan selama ini karena dengan banyaknya pro kontra dalam pendidikan jasmani yang berkaitan dengan olahraga kompetisi. Ketika pembelajaran jasmani mengaku untuk mempromosikan belajar siswa di domain kognitif, psikomotor, dan afektif penggunaan kegiatan kompetitif sebagai pengalaman belajar dipertanyakan (Brown \&
Grineski, 1992). Persaingan dapat menghambat pembelajaran dan memberikan sifat negatif (seperti: kecurangan dan kekerasan) (Brown \& Grineski, 1992). Siswayangmengalamikegagalan dalam persaingan mengalami penurunan harga diri dan kepercayaan diri (Campbell, 1974; Fait \& Billing, 1974; Greendorfer, 1987; Kohn, 1986). Sehingga mengalami penurunan motivasi dalam pembelajaran (Campbell, 1974; Fait \& Billing, 1974). Dalam pendidikan jasmani kegiatan kompetisi dapat dikatakan "zero sum" dimana ada pemenang dan pecundang, ada tim pemenang dan ada tim pecundang (Brown \& Grineski, 1992). Dari pro kontra tersebut maka dengan menggunakan SEM hal tersebut dapat teratasi, ini berkaitan dengan pernyataan ketika persaingan diberikan dengan cara yang tepat atau bisa dengan model pembelajaran yang tepat dapat memberikan rasa yang aman dalam proses pembelajaran (Ginanjar, Suherman, Juliantine, \& Hidayat, 2018).

Ada beberapa rekomendasi yang dianjurkan dalam penggunaan kegiatan kompetisi dengan menggunakan SEM yaitu hindari katakata ada pemenang, gunakan kesempatan untuk menghasilkan pelajaran yang memupuk perkembangan siswa yang positif, berikan penghargaan dalam setiap kegitan, kenali setiap tim dan individu, dan have fun (Almond, 2014). Dari rekomendasi tersebut hindari kata-kata ada pemenang dan ada yang kalah dalam penggunaan SEM menyediakan format dimana kemenangan lebih dari sekadar mencetak lebih banyak poin daripada tim lainnya, tujuannya adalah agar siswa memiliki pemahaman yang jelas tentang semua aspek olahraga, daripada hanya memiliki satu perspektif sebagai pemain.

Guru memiliki kesempatan unik untuk menghasilkan pelajaran yang memupuk perkembangan siswa yang positif dengan berfokus pada pengembangan siswa, bukan hasil dari permainan, guru dapat membantu siswa berkembang dalam lingkungan pencapaian. Berikan penghargaan dalam setiap kegiatan yang dilakukan seperti jika siswa mengalami kesulitan bekerja bersama sebagai tim, penekanan dapat ditempatkan pada afiliasi tim. Guru dapat memberi penghargaan kepada tim yang memenuhi tujuan untuk bekerja bersama dengan cara yang positif. Kenali setiap tim dan individu yang berprestasi setiap prestasi yang dicapai dapat ditampilkan dalam papan pengumuman, 


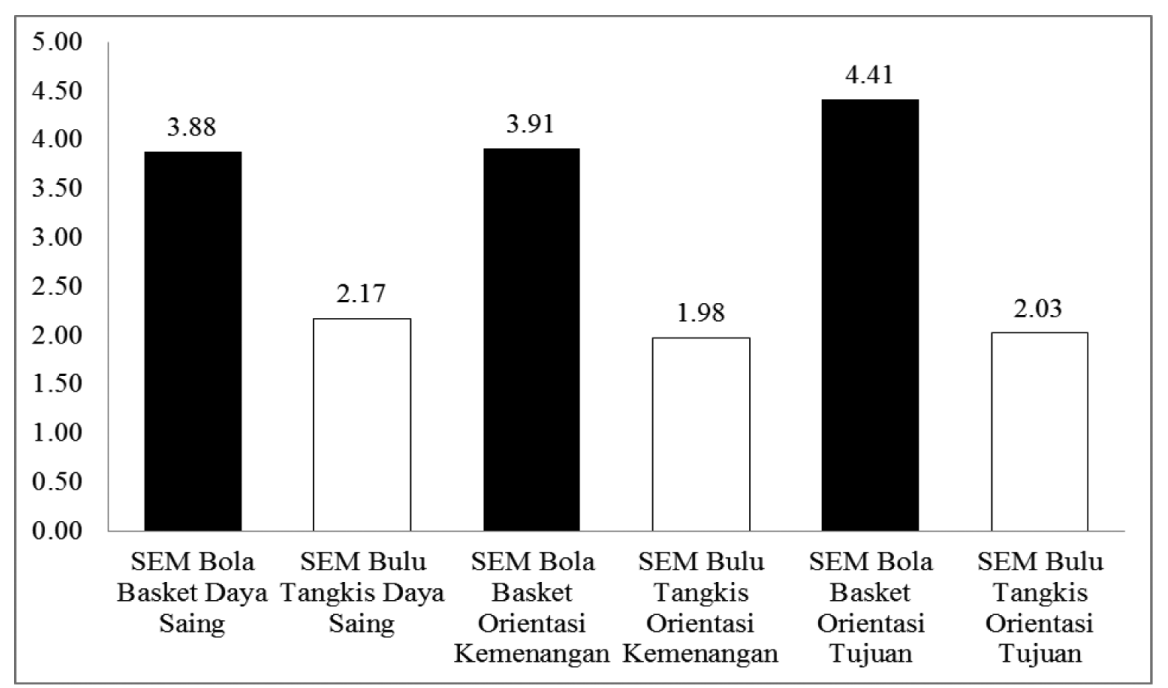

Gambar 1. Perbedaan Orientasi Olahraga pada Setiap Kelas Penelitian

jangan biarkan pembelajaran menjadi terlalu kompetitif, fokus yang diharapkan bukan hasil tetapi proses tetaplah fokus dalam hal yang mendasar yaitu proses pembelajaran bukan hasil yang didapatkan. Saat masalah datang tetaplah untuk Have fun!

Dalampencapaianorientasiolahragadalam pembelajaran pendidikan jasmani khususnya, dapat meningkat apabila guru menggunakan model pembelajaran yang tepat dalam proses pembelajarannya. Dengan menggunakan SEM yang menggunakan orientasi olahraga hal tersebut dapat teratasi karena SEM merupakan bentuk model pembelajaran kurikulum yang berdasarkan kepada teori bermain secara berkompetisi dengan hasil kompetisi tergantung kepada keterampilan dan strategi (Jewett, et al., 1995), lebih lanjut SEM dirancang untuk memberikan anak-anak dengan persaingan yang sesuai perkembangannya(Siedentop, etal., 2011). Guru harus dapat menganalisis yang menjadi kelemahan siswa dalam proses pembelajaran, sehingga dapat memperbaiki kelemahan tersebut dan mendorong siswa dalam memecahkan masalah-masalah dalam proses pembelajaran kehidupan siswa sehari-hari. Oleh karena itu, SEM dapat dijadikan akternatif yang sangat efektif bagi guru dalam pencapaian kegiatan kompetisi dalam pencapaian keberhasilan proses pembelajaran pendidikan jasmani.

Hasil yang menarik berkaitan dengan orientasi olaharaga yang didapat menggunakan SOQ yang terdiri dari subskala: 1) daya saing; 2) orientasi kemenangan; dan 3) orientasi tujuan. Pada kelas eksperimen subskala orientasi tujuan merupakan subskala yang paling berperan dalam orientasi olahraga dengan nilai rata-rata 4.41, kemudian subskala orientasi kemenangan merupakan subskala kedua yang paling berperan dalam orientasi olahraga dengan nilai rata-rata 3.91, dan subskala daya saing merupakan subskala ketiga yang paling berperan dalam orientasi olahraga dengan nilai rata-rata 3.88. Dari hasil tersebut pada kelompok SEM cabang olahraga tim orientasi olahraga dipengaruhi oleh orientasi tujuan disusul dengan orientasi kemenangan. Ini berkaitan dengan pernyataan yang menyatakan orientasi tujuan dan kemenangan mencerminkan pilihan dan respons individu selama latihan dan kegiatan olahraga (Jamshidi, Hossien, Sajadi, Safari, \& Zare, 2011). Oleh karena itu hasil ini mendukung pernyataan pencapaian dalam kompetisi olahraga (orientasi olahraga) tergantung pada orientasi tujuan (Farshad, et al., 2013; Sheikh, et al., 2011). Pada kelas kontrol subskala daya saing merupakan subskala yang paling berperan dalam orientasi olahraga dengan nilai rata-rata 2.17 , kemudian subskala orientasi tujuan merupakan subskala kedua yang paling berperan dalam orientasi olahraga dengan nilai rata-rata 2.03, dan subskala orientasi kemenangan merupakan subskala ketiga yang paling berperan dalam orientasi olahraga dengan nilai rata-rata 1.98. Hal ini bisa disebabkan oleh pemilihan cabang olahraga bulu tangkis yang mana siswa berperan secara individu, sehingga penelitian ini memberikan pandangan yang sesuai dengan pernyataan bahwa daya saing sangat menentukan seseorang untuk berpartisipasi dalam orientasi olahraga. Individu yang sangat berorientasi pada 
daya saing termotivasi untuk mencari prestasi dalam olahraga kompetitif (Jamshidi, et al., 2011). Oleh karena itu, hasil ini berbeda dengan pernyataan bahwa pencapaian dalam kompetisi olahraga (orientasi olahraga) tergantung pada orientasi tujuan (Farshad, et al., 2013; Sheikh, et al., 2011). Untuk perbedaan setiap orientasi olahraga pada kelas eksperimen maupun kelas kontrol dapat dilihat pada Gambar 1.

Dari hasil perbedaan rata-rata dari setiap subsakala tersebut juga memberikan pandangan bahwa dalam proses pendidikan jasmani yang berorientasikan olahraga dengan menggunakan SOQ (Ginanjar, 2018), pada SEM yang menggunakan cabang olah tim lebih diorientasikan kepada orientasi tujuan, ini sesuai dengan apa yang dikatakan oleh (Gill \& Deeter, 1988; Jamshidi, et al., 2011) yang menyatakan mereka yang memiliki orientasi tujuan fokus pada pencapaian tujuan pribadi dalam olahraga dan mengevaluasi keberhasilan dibandingkan dengan diri mereka sendiri. Dari pernyataan tersebut jelas bahwa dalam SEM menggunakan cabang olahraga tim, siswa lebih memikirkan pencapain tujuan pribadi dalam tim dibandingkan dengan individu masing-masing. Berbanding terbalik dengan SEM yang menggunakan cabang olah individu yang lebih diorientasikan kepada daya saing, ini berkaitan dengan pernyataan bahwa individu yang sangat berorientasi pada daya saing termotivasi untuk mencari prestasi dalam olahraga kompetitif (Jamshidi, et al., 2011).

\section{SIMPULAN}

Hasil penelitian menyimpulkan bahwa terdapat perbedaan SEM cabang olahraga tim dan SEM cabang olahraga individu terhadap orientasi olahraga dalam pendidikan jasmani Siswa SMP. Pada kelas eksperimen orientasi olahraga lebih dipengaruhi oleh orientasi tujuan ini sesuai dengan pernyataan bahwa pencapaian dalam kompetisi olahraga (orientasi olahraga) tergantung pada orientasi tujuan, tetapi pada kelas kontrol orientasi olahraga lebih dipengaruhi oleh daya saing, ini berbeda dengan apa yang dinyatakan sebelumnya. Oleh karena itu, penelitian ini menyarankan agar penelitian yang lebih lanjut dengan menggunakan partisipan yang lebih banyak dan dengan melibatakan siswa perempuan untuk lebih membuktikan hasil temuan yang telah didapat. Selain itu, agar melakukan penelitian dengan menggunakan
Sport Education Model tim dan Sport Education Model individu dengan menggunakan cabang olahraga yang lainnya tergantung dengan apa yang menjadi permasakah dalam penelitian yang disesuaikan dengan pengetahuan dengan cabang olahraga yang akan dipilih.

\section{UCAPAN TERIMA KASIH}

Penulis ucapkan terima kasih kepada Kementerian Riset, Teknologi, dan Pendidikan Tinggi yang telah memberikan penulis dana dan kesempatan melanjutkan studi serta memperoleh hibah skema kompetitif nasional.

\section{DAFTAR PUSTAKA}

Almond, L. (2014). Does competitive sport have educational validity in physical education? Science \& Sports, 29(October), S51-S54. doi:10.1016/j.scispo.2014.08.102.

Arnold, P. J. (1989). Competitive sport, winning and education. Journal of Moral Education, 18(1), 15-25. doi:10.1080/0305724890180102.

Bennett, G., \& Hastie, P. A. (1997). A sport education curriculum model for a collegiate physical activity course. Journal of Physical Education, Recreation \& Dance, 68(1), 39-44. doi:10.1080/07303 084.1997.10604876.

Brown, L., \& Grineski, S. (1992). Competition in physical education: An educational contradiction? Journal of Physical Education, Recreation \& Dance, 63(1), 17-77. doi:10.1080/07303084.1992.1060 4080 .

Bryan, C. L., \& Solmon, M. A. (2012). Student motivation in physical education and engagement in physical activity. Journal of Sport Behavior, 35(3), 267-285.

Campbell, D. N. (1974). On being number one: Competition in education. Phi Delta Kappan, 56(2), 143-146.

Carlson, T. (1995). " Now, I think I can": The reaction of eight low-skilled students to sport education . ACHPER Healthy Lifestyle Journal, 150, 6-8. 
Curtner-Smith, M. D., Todorovich, J. R., McCaughtry, N. A., \& Lacon, S. A. (2001). Urban teachersi use of productive and reproductive teaching styles within the confines of the national curriculum for physical education. European Physical Education Review, 7(2), 177-190. doi:10.1177/1356336X010072005.

Fait, H., \& Billing, J. (1974). Reassescment of the value of competition. In G. McGlyn (Ed.), Issues in physical education and sports (1st ed.). Palo Alto, CA: National Press.

Farshad, T., Jasem, M., \& Mohammad, M. (2013). Validation of an instrument for measuring athletes, sport orientation in Iranian martial artists community. MiddleEast Journal of Scientific Research, 18(6), 738-743. doi:10.5829/idosi. mejsr.2013.18.6.75140.

Fraenkel, J. R., Wallen, N. E., \& Hyun, H. H. (2013). How to design and evaluate research in education. New York, NY: McGraw-Hill Education.

Gill, D. L., \& Deeter, T. E. (1988). Development of the sport orientation questionnaire. Research Quarterly for Exercise and Sport, 59(3), 191-202. doi:10.1080/0270 1367.1988.10605504.

Gill, D. L., \& Dzewaltowski, D. (1988). Competitive orientations among intercollegiate athletes: Is winning the only thing. The Sports Psychologist, 2(3), 212-221. doi:10.1123/tsp.2.3.212.

Ginanjar, A. (2015). The influence of inquiry method in motivating the SMP' student. Jurnal Kependidikan, 45(2), 123-129. doi:10.21831/jk.v45i2.7489.

Ginanjar, A. (2018). Pengaruh sport education model bulu tangkis terhadap orientasi olahraga siswa SMP. BIORMATIKA, 4(2), 280-287. Retrieved from http:// ejournal.unsub.ac.id/index.php/FKIP/ article/view/379.
Ginanjar, A., Suherman, A., Juliantine, T., \& Hidayat, Y.(2018). Competitive in physical education using sports education model. 3rd International Conference on Sports Science, Health and Physical Education. Bandung: FPOK UPI Bandung.

Greendorfer, S. L. (1987). Psycho-social correlates of organized physical activity. Journal of Physical Education, Recreation \& Dance, 58(7), 59-64. doi:10.1080/0730 3084.1987.10609604.

Hastie, P. A., \& Curtner-smith, M. D. (2006). Influence of a hybrid sport education Teaching games for understanding unit on one teacher and his students. Physical Education and Sport Pedagogy, 11(1), 1-27. doi:10.1080/17408980500466813.

Hastie, P. A., \& Sinelnikov, O. A. (2006). Russian students' participation in and perceptions of a season of sport education. European Physical Education Review, 12(2), 131150. doi:10.1177/1356336X06065166.

Hastie, P. A., \& Trost, S. G. (2002). Student physical activity levels during a season of sport education. Pediatric Exercise Science, 14(1), 64-74. doi:10.1123/ pes.14.1.64.

Jamshidi, A., Hossien, T., Sajadi, S. S., Safari, K., \& Zare, G. (2011). The relationship between sport orientation and competitive anxiety in elite athletes. Procedia-Social and Behavioral Sciences, 30(2011), 11611165. doi:10.1016/j.sbspro.2011.10.226.

Jewett, A. E., Bain, L. L., \& Ennis, C. D. (1995). The curriculum process in physical education ( $2^{\text {nd }}$ ed.). Madison: WCB Brown \& Benchmark.

Kemendikbud. (2012). Kurikulum SMP 2013. Jakarta: Kementerian Pendidikan dan Kebudayaan.

Kirk, D., \& Mcdonald, D. (1998). Situated learning in physical education. Journal of Teaching in Physical Education, 17(3), 376-387. doi:10.1123/jtpe.17.3.376. 
Kohn, A. (1986). No contest: the case against competition. Boston: Houghton Mifflin Company.

Komnaspenjasor. (2009). Menuju pendidikan jasmani dan olahraga berbasis riset. Jakarta: Kementerian Negara Pemuda dan Olahraga Republik Indonesia.

Maksum, A. (2008). Kualitas guru pendidikan jasmani di sekolah: Antara harapan dan kenyataan. Makalah disampaikan dalam Simposium tahunan penelitian pendidikan, 12-14 Agustus 2008, Jakarta.

Manouchehri, J., \& Tojari, F. (2013). Examining the conceptual model: Relationships between sport orientation, doping attitude and doping behavior in Iranian elite martial artists. European Journal of Experimental Biology, 3(2), 175-182.

McPhail, A., Gorely, T., Kirk, D., \& Kinchin, G. (2008). Children's experiences of fun and enjoyment during a season of sport education. Research Quarterly for Exercise and Sport, 79(3), 344-355. doi:1 $0.1080 / 02701367.2008 .10599498$.

McPhail, A., Kirk, D., \& Kinchin, G. (2004). Sporteducation: Promoting team affiliation through physical education. Journal of Teaching in Physical Education, 23(2), 106-122. doi:10.1123/jtpe.23.2.106.

Metzler, M. W. (2000). Intructional models for physical education. Massachusetts: Allyn and Bacon.

Perlman, D. (2010). Change in affect and needs satisfaction for amotivated students within the sport education model. Journal of Teaching in Physical Education, 29, 433445. doi:10.1123/jtpe.29.4.433.

Perlman, D. (2012). The influence of the sport education model on amotivated students' in-class physical activity. European Physical Education Review, 18(3), 335345. doi:10.1177/1356336X12450795.
Petróczi, A. (2007). Attitudes and doping: a structural equation analysis of the relationship between athletes' attitudes, sport orientation and doping behaviour. Substance Abuse Treatment Prevention and Policy, 2(1), 1-9. doi:10.1186/1747597X-2-Received.

Roberts,S.,\&Fairclough,S.(2011).Observational analysis of student activity modes, lesson contexts and teacher interactions during games classes in high school (11-16 years) physical education. European Physical Education Review, 17(2), 255268. doi:10.1177/1356336X11420222.

Sheikh, M., Afshari, J., \& Sheikh, H. (2011). Comparing sport orientation between individual and team sports and its relation to sport participation motivation. American Journal of Scientific Research, 30(2011), 28-35.

Siedentop, D. (1994). Sport education: quality $P E$ through positive sport experiences. Champaign: Human Kinetics.

Siedentop, D. (1998). What is sport education and how does it work? Journal of Physical Education, Recreation \& Dance, 69(4), 18-20. doi:10.1080/07303084.1998.1060 5528.

Siedentop, D., Hastie, P. A., \& van der Mars, H. (2011). Complete guide to sport education ( 2 ed.). Champaign, IL: Human Kinetics.

Skordilis, E. K., Koutsouki, D., Asonitou, K., Evans, E., Jensen, B., \& Wall, K. (2001). Sport orientations and goal perspectives of wheelchair athletes. Adapted Physical Activity Quarterly, 18(3), 304-315. doi:10.1123/apaq.18.3.304.

Wallhead, T. L., \& Ntoumanis, N. (2004). Effects of a sport education intervention on students' motivational responses in physical education. Journal of Teaching in Physical Education, 23(1), 4-18. doi:10.1123/jtpe.23.1.4. 